\title{
Effects of scopolamine on retention of taste-aversion learning in rats
}

\author{
FRANK J. GADUSEK and JAMES W. KALAT \\ Duke University, Durham, North Carolina 27706
}

\begin{abstract}
Rats were poisoned 90 min after drinking a novel sucrose solution. Two or four days later, they were tested for learned aversions to sucrose while under the influence of various doses of scopolamine. In three replications, the evidence failed to indicate any substantial effect of scopolamine on retention of learned taste aversions. It is suggested that taste-aversion learning may be less dependent on changes in cholinergic synapses than are certain other types of learning.
\end{abstract}

J. A. Deutsch (1973) has described a bold set of tests of the commonly held hypothesis that learning and memory are due to an altered conductance at $\mathrm{ACh}$ synapses. He described an impressive array of experiments linking central cholinergic synaptic changes to visual discrimination learning for shock escape in rats. His conclusions were that: (1) anticholinergics, such as scopolamine and atropine, interfere with poorly remembered behaviors and have much less effect on strong memories, and (2) anticholinesterases, such as DFP and physostigmine, facilitate poorly remembered behaviors and may interfere with well-remembered behaviors by producing synaptic block.

The generality of Deutsch's conclusions may be evaluated by testing for similar results in other learning situations. Taste-aversion learning seems to represent a specific evolutionary adaptation with behavioral parameters substantially different from those found for other types of learning (Rozin \& Kalat, 1971). A number of brain-lesion studies suggest that the physiology may differ from that of other learning paradigms as well (e.g., Hobbs \& Elkins, 1974; Kral, 1972; McGowan, Garcia, \& Ervin, 1969). Thus, it may be interesting to test whether taste-aversion learning depends on changes in acetylcholine synapses to anything like the extent that visual discriminations for shock escape do. Smith and Morris (1964) and Kral (1971) found that atropine or scopolamine injections before or during the original taste-poison pairing had no effect on taste-aversion learning; however, there have been no previous studies of the effect of anticholinergic drugs on the retention of already-learned aversions.

In Experiments I-III, rats first learned an aversion to sucrose. On a subsequent test session, the strength of the aversion after injection of various doses of scopolamine hydrobromide was compared to that of controls injected with saline. According to Deutsch's hypotheses, a given scopolamine dose should produce more decrement on a

This research was supported by an'Alfred P. Sloan Fellowship to the second author. We thank Beth Nathan for comments on the manuscript.

Address reprint requests to J. W. Kalat, Department of Psychology, Duke University, Durham, North Carolina 27706. weak memory than on a strong memory. However, even with a strong taste-aversion memory, a very large dose should produce some amnesia.

\section{EXPERIMENTS I, II, AND III}

\section{Methods}

Rats were kept in individual wire cages containing openings for two $30-\mathrm{ml}$ Richter tubes with $.5-\mathrm{ml}$ gradations. Each was allowed to drink tap water for $1 \mathrm{~h}$ each morning until all rats were drinking immediately after presentation. The rats had ad-lib access to Purina Lab Chow at all times.

In Experiment I, subjects were 45 rats bred in the authors' laboratory, from a genetically heterogeneous colony, ages 48-67 days. They were divided into 5 groups of 9 rats each. Table 1 summarizes the procedures for each group. All were presented with a novel $10 \%$ sucrose solution for $2.5 \mathrm{~min}$. Ninety minutes later, rats in Groups $0, .05, .5$, and 1.0 were intubated with $1 \mathrm{ml}$ $.15 \mathrm{M} \mathrm{LiCl}$ per $30 \mathrm{mg}$ body weight, while the no-poison control-group rats were intubated with isotonic saline. Four days after poisoning, the groups which had been intubated with $\mathrm{LiCl}$ were injected subcutaneously with scopolamine hydrobromide (Matheson, Coleman, \& Bell) at doses of 0 (saline control), .05, .5 , or $1.0 \mathrm{mg} / \mathrm{kg}$. The scopolamine was dissolved in isotonic saline and its concentration adjusted so that each rat received approximately $.5 \mathrm{ml}$ of the solution. Thirty minutes after injection, subjects were presented with the test sucrose and water solutions. The experimenter recorded the amount each rat drank of each solution during the following $30 \mathrm{~min}$.

Experiments II and III followed the same general procedures as Experiment I, with the following exceptions: In Experiment II, subjects were 44 rats, 31-57 days old. A 45 th rat was eliminated because it failed to drink anything on the test day. In an effort to minimize the floor effect which occurred in Experiment I, a 60 -min test was conducted instead of a 30 -min test, and larger scopolamine doses were used, as indicated in Table 1. The delay between poisoning and test was reduced from 4 days to 2 days in an effort either to find parameters under which a large effect would occur, or to demonstrate some generality of negative findings.

In Experiment III, subjects were 35 rats, $40-66$ days old. A 36 th rat was eliminated because it failed to drink any of either solution on the test day. Scopolamine doses and other parameters are given in Table 1.

\section{Results}

Although the poisoning procedure was the same in all three experiments, the level of acquired aversion to sucrose varied, being greatest in Experiment $I$ and least 
Table 1

Summary of Procedures for Experiments I, II, and III

\begin{tabular}{clccc}
\hline Group & Poison? & $\begin{array}{c}\text { Delay } \\
\text { to Test } \\
\text { (Days) }\end{array}$ & $\begin{array}{c}\text { Scopol- } \\
\text { amine } \\
\text { (mg/kg) }\end{array}$ & $\begin{array}{c}\text { Test } \\
\text { Period } \\
\text { (Min) }\end{array}$ \\
\hline $\begin{array}{c}\text { Experiment I } \\
0\end{array}$ & Yes & 4 & 0 (Saline) & 30 \\
.05 & Yes & 4 & .05 & 30 \\
.5 & Yes & 4 & .5 & 30 \\
1 & Yes & 4 & 1 & 30 \\
No Poison & Saline & 4 & .5 & 30 \\
Experiment II & & & & \\
0 & Yes & 2 & 0 (Saline) & 60 \\
.5 & Yes & 2 & .5 & 60 \\
2 & Yes & 2 & 2 & 60 \\
10 & Yes & 2 & 10 & 60 \\
No Poison & Saline & 2 & 2 & 60 \\
Experiment III & & & & \\
0 & Yes & 4 & 0 (Saline) & 60 \\
.5 & Yes & 4 & .5 & 60 \\
10 & Yes & 4 & 10 & 60 \\
No Poison & Saline & 4 & 10 & 60 \\
\hline
\end{tabular}

Note-All groups drank novel $10 \%$ sucrose for $2 \frac{1}{2}$ min, followed 90 min later by intubation of $1 \mathrm{ml} / 30 \mathrm{~g}$ body weight.15M LiCl. Two or 4 days later, the rats were given the two-bottle tests, sucrose i's. water, for the period indicated.

in Experiment II. Figure 1 presents the mean volume of sucrose ingested and the mean percent sucrose ingested for each group. These measures are not perfectly correlated with each other because increasing doses of scopolamine reduced the total fluid drunk. This poses problems in data interpretation, as discussed below.

The results of each of the three experiments were subjected to an analysis of variance with regard to both sucrose consumption and percent sucrose preference. In each case, the ANOVA was significant $(\mathrm{p}<.025)$ when all groups were considered. However, the main question under consideration was whether the scopolamine groups would have a weaker sucrose aversion than the saline controls, Group 0: and, if so, whether this amnesic effect would be dose-dependent. When the no-poison control group was eliminated from consideration, an ANOVA of the remaining groups was not significant $(p>.05)$, with one exception to be described below. That is, the no-poison group differed significantly from the poisoned groups, but there were no significant differences among the poisoned groups. In other words, there was no evidence that scopolamine significantly affected retention of the learned aversion to sucrose.

The only exception to this pattern was the sucrose volume data for Experiment II. In this case, the analysis of variance indicated a significant difference $(p<.05)$ between Groups 0 and 2, 0 and 10, and .5 and 2 .

\section{Discussion}

The 90-min taste-poison delay was selected for this experiment because past results indicated that it produced an intermediate level of aversion (Kalat \&
Rozin, 1971); thus. drug effects might be seen in the absence of either floor effects or ceiling effects. For unknown reasons, though the taste-poisoning procedure was the same in Experiments I-III, the resultant learned aversions differed in magnitude. Therefore, it is possible to examine the effect of scopolamine on three different levels of learned aversion.

Scopolamine, in addition to possible amnesic effects, reduces thirst. For instance, in Experiment III, Group 0 had a mean total liquid intake of $14.4 \mathrm{ml}$, while Group 10 had a mean of $4.4 \mathrm{ml}$. This poses potentially serious problems in the interpretation of data, since it is possible that a drug could cause decreased intake of a solution, yet increased percent preference for it. According to the volume measure, the drug would have caused increased aversion; according to the percent preference measure, it would have produced decreased aversion. Which, if either, is the better measure?

A definitive answer cannot be provided at this time. Fortunately, an answer is not necessary for the interpretation of the present results, since the drug failed to produce a reliable increase or decrease according to either measure.

Significant differences among the poisoned experimental groups were found only in Experiment II, and there only for the volume data. In Experiment II, increasing scopolamine doses led to decreased sucrose consumption, which must be accounted for in terms of
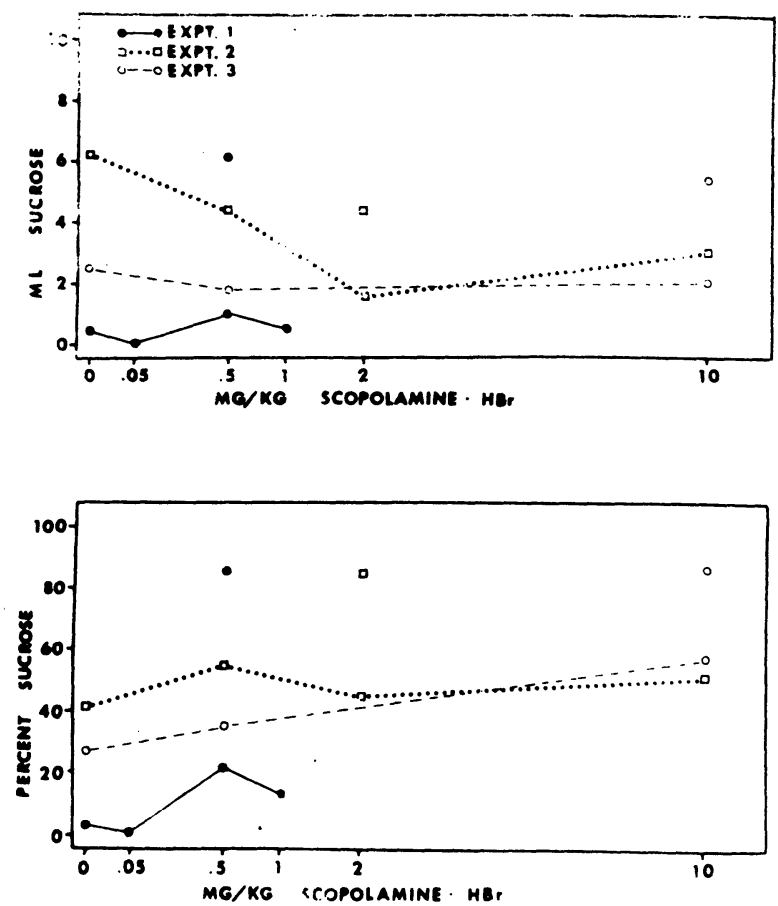

Figure 1. Sucrose intake, expressed as milliliters in top section and as percent preference in bottom section, as a function of scopolamine dose given $\mathbf{3 0} \mathrm{min}$ prior to test. No-poison control groups are indicated by the dots not on the lines. 
decreased thirst rather than in terms of amnesia. This interpretation is strengthened by the fact that the no-poison controls in Experiment II, which were also injected with $2 \mathrm{mg} / \mathrm{kg}$ scopolamine, also drank a relatively small amount of sucrose. In none of the three experiments did scopolamine significantly affect percent preference for sucrose.

The only suggestion of a scopolamine-dose-dependent trend was the increase in percent preference for sucrose in Experiment III. These results, though not statistically significant, may be worthy of further note. With increasing doses of scopolamine, the rats showed no change in sucrose intake, but a steady decline in water intake, yielding a net increase in percent consumption of sucrose. Preliminary data (Jones \& Kalat, unpublished data, 1974) indicate a similar effect of naturally occurring thirst on learned taste aversions: with decreasing thirst, rats drank similar amounts of sucrose but decreased their water intake, as if the effect of the learned aversion was to limit how much of the solution the animal was willing to drink, regardless of his fluid needs.

Overall, the present results indicate that scopolamine had little effect on retention of moderately strong learned taste aversions to sucrose, in contrast to the large effects reported in visual discriminations for shock escape (Deutsch, 1973). The most interesting interpretation of this difference is that taste-aversion learning depends on a different neurotransmitter system from those involved in other types of learning. This case could be strengthened by examining the effects of other cholinergic and anticholinergic drugs on taste-aversion learning, and by examining the effects of drugs known to affect other types of synapses.

\section{REFERENCES}

Deutsch, J. A. The cholinergic synapse and the site of memory. In J. A. Deutsch (Ed.), The physiological basis of memory. New York: Academic Press, 1973.

Hobbs, S. H., \& Elkins, R. L. Taste-aversion conditioning in rats with septal lesions. Behavioral Biology, 1974.

Kalat, J. W., \& Rozin, P. Role of interference in taste-aversion learning. Journal of Comparative and Physiological Psychology, 1971, 77, 53-58.

Kral, P. A. Effects of scopolamine injection during CS-US interval on conditioning. Psychological Reports, 1971, 28, 690.

Kral, P. A. Localized ECS impedes taste-aversion learning. Behavioral Biology, 1972, 7, 761-765.

McGowan, B. K., Garcia, J., Ervin, F. R., \& Schwartz, J. Effects of septal lesions on bait shyness in the rat. Physiology \& Behavior, 1969, 4, 907-909.

Rozin, P., \& Kalat, J. W. Specific hungers and poison avoidance as adaptive specializations of learning. Psychological Review, $1971,78,459-486$

Smith, J. C., \& Morris, D. D. The effects of atropine sulfate and physostigmine on the conditioned aversion to saccharin solution with $x$-rays as the unconditioned stimulus. In $T$. J. Haley and R. S. Snider (Eds.), Response of the nervous system to ionizing radiation: Second international symposium. Boston: Little, Brown, 1964.

(Received for publication August 13, 1974; revision received October 24,1974 .) 